\title{
O-ring Wage Inequality
}

\author{
By Alberto Dalmazzo $\dagger$, Tuomas Pekkarinen $\ddagger$ and Pasquale Scaramozzino \\ $\dagger$ †ipartimento di Economia Politica, Universita’ di Siena $\quad \ddagger$ Uppsala University \\ §Dipartimento di Economia e Istituzioni, Universita' di Roma Tor Vergata, and DeFiMS, SOAS, \\ University of London
}

Final version received 26 January 2006.

\begin{abstract}
We examine the relationship between technological complexity and wage inequality, using an efficiency wage model that adopts Kremer's O-ring production function. The model has two main implications: (i) when the production process becomes more complex, within-task wage differences increase between plants, and (ii) between-task wage differences increase within plants. We study these implications empirically using industry data providing quantified information on the complexity of the tasks. We find that wages increase in all the tasks with the complexity of the production process. Furthermore, the relationship between the complexity of the tasks and wages is steepest in the firms with more complex production processes.
\end{abstract}

\section{INTRODUCTION}

The last decades have witnessed important changes both in the production structure and in wage dispersion, leading many observers to conclude that new technologies are closely related to rising wage inequality. The most prominent hypothesis is that the introduction of advanced technologies has caused a strong increase in the demand for skilled workers. ${ }^{1}$ Kremer and Maskin (1996) have suggested that technological change may have contributed substantially to increasing segregation of workers of different quality into high-wage and low-wage firms. Less attention has been paid to the relation between technological change and increasing within-group wage inequality, or residual variation, mostly attributed to unobserved worker ability. ${ }^{2}$ However, according to Abowd et al. (1999a, 1999b), individual ability alone cannot entirely explain wage differentials: employers' effects are still found to be relevant. The scope of this paper is to provide a theoretical and empirical analysis of the relation between complex technologies and wage structure. In particular, our approach can explain why identical workers may receive different wages in equilibrium, and why complex technologies may increase wage inequality among co-workers.

The first part of the paper substantively extends the theoretical model developed in Dalmazzo (2002), where technology is represented by Kremer's (1993) 'O-ring' production function and firms pay efficiency wages. Here, similarly to Kremer and Maskin (1996), we postulate that production requires the execution of a certain number of 'easy' and 'hard' tasks, characterized by a different sensitivity to effort. Both the number and the composition of tasks are measures of technological complexity since, if even a single task is mis-performed, output is lost. Such a notion of technology implies the existence of strong complementarities among the tasks, or activities, that constitute the production process. ${ }^{3}$ As in Dalmazzo (2002), we show that when monitoring is imperfect the employer will have an incentive to pay wages that induce employees to elicit a proper level of effort. When the degree of complexity in production is relatively high, the employer will pay higher wages on average. ${ }^{4}$ The model proposed here, however, 
provides additional insights. Since different tasks have a different sensitivity to effort, we are also able to analyse the employer's wage policy within the plant.

Our model implies that plants with relatively more complex production processes have incentives to pay higher wages to workers in all the tasks. This happens because greater complexity increases the risk of failure in the production process. Thus, when some plants become more complex than others, the within-task wage differences will increase between plants. Moreover, because output in more complex tasks is more sensitive to a worker's effort, the increased complexity will have stronger wage effects in complex tasks. Hence, within plants, a more complex production process will increase the wage differences between tasks. ${ }^{5}$

In the empirical part of the paper, we consider how individual hourly wages are affected by changes in the complexity of the plant's production process. We have access to unique data where the complexity of the worker's tasks is proxied by a task-specific minimum wage. In the Finnish metal industry each job is assigned a minimum wage according to the complexity of the tasks it requires. This feature of the data overcomes a major difficulty in the empirical implementations derived from O-ring theory, since we can now proxy the complexity of the worker's tasks with a continuous variable. Furthermore, the linked employer-employee panel nature of the data allows us to calculate the average task-specific minimum wages in each firm, which acts as a proxy for the complexity of the firm's production process.

We find that wages in all the tasks are increasing with the complexity of the production process. This relationship also holds when unobservable individual and plant characteristics are controlled for. Furthermore, the relationship between the complexity of the tasks and wages is steepest in the firms that have most complex production processes. These results are in line with the implications of the theoretical model.

The paper is structured as follows. Section I develops the basic theoretical model. In Section II, the data are presented. Particular emphasis is put on the explanations of the variables of interest. Section III presents the empirical results on the relation between technology, wage levels and within-plant wage dispersion. Section IV concludes.

\section{THE MODEL}

In this section we first develop the basic model of the employer's optimal behaviour when the production function has the O-ring form and workers can be imperfectly monitored. In Section I(b), we examine the effects of product market competition by characterizing a zero-profit equilibrium, and obtain the main predictions of the theory.

\section{(a) The basic framework}

In the model we develop, workers dislike effort and monitoring is imperfect. As in the efficiency-wage model by Summers (1988), we assume that the level of effort $e$ exerted by a worker is given by the following function:

$$
e=\left\{\begin{array}{ll}
\left(\frac{w-x}{x}\right)^{\beta}, & \text { if } w>x \\
0, & \text { if } w \leqslant x
\end{array}\right\}
$$

where $w$ is the wage paid, $x$ denotes the value of worker's labour-market alternatives, and $\beta \in(0,1)$. 
For what concerns technology, we borrow from Kremer (1993) the notion of the 'Oring production function'. Production requires that $n$ tasks be correctly performed. Here, as in Dalmazzo (2002), the probability that a task is carried out successfully depends on the effort put in by the worker who is in charge of it. Similarly to Kremer and Maskin (1996), production involves a number $l$ of 'easy' tasks $(l \leqslant n)$, and a number $(n-l)$ of 'hard' tasks. We assume that easy and hard tasks have a different sensitivity to effort. In particular, an easy task will be performed correctly with probability equal to $q=q(e)$, with $q^{\prime}>0$. On the other hand, a hard task will be performed correctly with probability $q^{z}=[q(e)]^{z}$, where $z>1$. Thus, given the level of effort put in, a hard task is less likely to succeed than an easy task. Without loss of generality, we assume that each task is performed by a single worker.

When (i) tasks have different difficulty, (ii) all workers assigned to hard tasks put in the same level of effort and (iii) all workers assigned to easy tasks put in the same level of effort, the revenues $y$ generated by the O-ring production function can be written as follows: ${ }^{6}$

$$
y=n B(n, l ; f) q^{l} \cdot q^{z(n-l)}
$$

where $B(n, l ; f)$ denotes the average revenue per worker when all the tasks are correctly performed, an event occurring with probability $q^{l} \cdot q^{z(n-l)}$; the variable $f$ denotes the number of identical firms in the industry; and we take $B_{f}<0$ : i e. the higher the number of competing firms, the lower the firm's revenues. Note that the production function (2) entails complementarity among tasks: as will be shown, the optimal wage to be paid for a certain task depends on the wage levels paid for all the other tasks, irrespective of whether they are easy or hard. This property follows directly from the technology considered: in the most extreme interpretation of Kremer (1993), the degree of integration among tasks is such that if only one task is mis-performed the value of production drops to zero.

In general, it can be useful to think of the model as if there were two types of worker: high-skilled (indexed by $h$ ) and low-skilled (indexed by $l$ ), assuming that workers of different skills cannot be substituted for one another. Then low-skill workers will be assigned to easy tasks, while high-skill workers will be assigned to hard tasks. ${ }^{7}$ For example, managerial tasks will be given to workers who meet particular requirements in terms of education, experience, etc. When there are common preferences towards labour disutility, equation (1) will hold for both types of worker, with $x_{h}$ and $x_{l}$ denoting respectively the high-skilled and the low-skilled labour-market opportunities $\left(x_{h} \geqslant x_{l}\right)$.

For simplicity, we take the probability $q$ to be equal to $e$. Hence the profit maximization problem takes the form

$$
\begin{aligned}
\max _{\left\{w_{l}, w_{h}\right\}} \Pi= & n \cdot B(n, l ; f)\left(\frac{w_{l}-x_{l}}{x_{l}}\right)^{\beta \cdot l}\left(\frac{w_{h}-x_{h}}{x_{h}}\right)^{z \beta \cdot(n-l)} \\
& -w_{l} l-w_{h}(n-l)-F
\end{aligned}
$$

where $F \geqslant 0$ represents a fixed cost in production and $\beta \cdot l+z \beta(n-l)<1$. The firm maximizes profit by choosing simultaneously the wage levels $w_{l}$ and $w_{h}$ paid to the workers assigned to easy and hard tasks, respectively.

The solution to problem (3) generates the following first-order conditions:

$$
\frac{\partial \Pi}{\partial w_{l}}=\frac{\beta y}{w_{l}-x_{l}}-1=0
$$




$$
\frac{\partial \Pi}{\partial w_{h}}=\frac{z \beta y}{w_{h}-x_{h}}-1=0,
$$

where $y$ is defined by (2). Note that the equilibrium wage level $w_{l}$ depends, through $y$, on the equilibrium wage level $w_{h}$, and vice versa. By manipulating (4) and (5), we can derive

$$
\frac{w_{h}-x_{h}}{w_{l}-x_{l}}=z
$$

Condition (6) implies that $\left(w_{h}-w_{l}\right)>\left(x_{h}-x_{l}\right)$. Thus, if the skilled workers' outside opportunities are better than for the unskilled workers (that is, if $x_{h}>x_{l}$ ), the employer will pay skilled workers a higher wage. ${ }^{8}$

We now concentrate on the effects of $n$ and $l$ on the equilibrium values of wages, $w_{h}$ and $w_{l}$. The number of tasks $n$ can be interpreted as a measure of complexity in production: given $l$, the greater the number of tasks, the greater the probability that something goes wrong and production is lost. On the other hand, given $n$, a greater number of easy tasks $l$ reduces the weight of hard - and riskier - tasks on the production process.

By differentiating the system (4)-(5), and exploiting the second-order conditions associated with problem (3), we obtain the following proposition.

Proposition 1. An increase in the number of tasks, $n$, will raise the wage paid to high-skilled workers whenever expected revenues are increasing in $n$ : hence it holds that $\mathrm{d} w_{h} / \mathrm{d} n>0$ if and only if $\mathrm{d} y / \mathrm{d} n>0$. Similarly, it holds that $\mathrm{d} w_{h} / \mathrm{d} l>0$ if and only if $\mathrm{d} y / \mathrm{d} l>0$.

Note also that when $\mathrm{d} w_{h} / \mathrm{d} n$ is positive, $\mathrm{d} w_{l} / \mathrm{d} n$ is positive as well, since $\left(w_{h}-x_{h}\right)=z\left(w_{l}-x_{l}\right)$. Analogously, when $\mathrm{d} w_{h} / \mathrm{d} l>0$, it will hold that $\mathrm{d} w_{l} / \mathrm{d} l>0$.

The implications of Proposition 1 need some discussion, because they crucially depend on the sign of $\mathrm{d} y / \mathrm{d} n$ and $\mathrm{d} y / \mathrm{d} l$. What are the plausible signs for $\mathrm{d} y / \mathrm{d} n$ and $\mathrm{d} y / \mathrm{d} l$ ? Consider first the case of a firm that is considering whether to implement a more complex technology (higher $n$ ). The technology will be adopted only when profitable, that is, only when the condition $\mathrm{d} \Pi / \mathrm{dn}>0$ holds. By the envelope theorem, it holds that $\mathrm{d} \Pi / \mathrm{d} n=\mathrm{d} y / \mathrm{d} n-w_{h}^{*}$. Consequently, it must be true that $\mathrm{d} y / \mathrm{d} n>0$. We can conclude that increasingly complex technologies will be implemented only when revenues $y$ are increasing in $n$ : this can occur for example when more sophisticated products sell at higher prices. Thus, as implied by Proposition 1, the adoption of more complex technologies is bound to raise wages.

We can now discuss the effect of a change in $l$. Given the degree of complexity in the technology considered (i.e. given $n$ ), a rise in $l$ implies that some 'hard' tasks can be transformed into 'easy', less risky, tasks. This occurs, for example, when certain tasks requiring a high level of skills can be reduced into 'routines' performed by lower paid workers. ${ }^{9}$ On balance, the net effect of changes in $l$ on $y$ is intrinsically ambiguous. On the one hand, a greater number of easy tasks, given $n$, reduces risk and increases revenues' expected value. On the other hand, it is reasonable to expect that the condition $B_{l}<0$ holds: products that rely on very standardized production methods are likely to sell at lower prices.

As shown in the following section, more precise predictions on the effects of $n$ and $l$ on wage levels can be obtained by considering competition among firms.

(C) The London School of Economics and Political Science 2006 


\section{(b) The effects of competition}

Proposition 1 holds for a given number of firms, $f$. In this section we consider product market competition through the entry of new firms, in order to obtain sharper predictions from comparative statics. To this purpose, we impose that the zero-profit condition holds. This condition takes the form ${ }^{10}$

$$
y=w_{l} \cdot l+w_{h}(n-l)+F .
$$

Exploiting condition (7) together with (4)-(5), one obtains the following system of two equations in $\left(w_{l}, w_{h}\right)$ :

$$
\begin{aligned}
& \beta\left[w_{l} \cdot l+w_{h}(n-l)+F\right]-\left(w_{l}-x_{l}\right)=0, \\
& z \beta\left[w_{l} \cdot l+w_{h}(n-l)+F\right]-\left(w_{h}-x_{h}\right)=0 .
\end{aligned}
$$

By totally differentiating (8)-(9) with respect to $\left(w_{h}, w_{l}, n, l, F\right)$, we obtain the following result. $^{11}$

Proposition 2. Under the zero-profit equilibrium, it holds that: (i) $\mathrm{d} w_{h} / \mathrm{d} n$ and $\mathrm{d} w_{l} / \mathrm{d} n$ are positive, and (ii) $\mathrm{d} w_{h} / \mathrm{d} l$ and $\mathrm{d} w_{l} / \mathrm{d} l$ are negative.

Proposition 2 has some relevant implications. First, when the employer adopts a relatively complex technology (i.e. when $n$ is high in our model), it will be ready to pay relatively high wages to its employees, irrespective of whether they are attached to hard or easy tasks. Higher complexity raises the risk of failure in production. Thus, since tasks are complementary, the employer will have an incentive to elicit more effort from every employee. In this perspective, wage inequality tends to arise mainly through 'plant segregation': there are high-wage plants and low-wage plants according to the type of technology adopted. ${ }^{12}$

Empirically, it is a well known fact that inter-firm wage differentials are related to observable differences in the production technologies. This result has been reported in studies such as Dunne et al. (2004), Dunne and Schmitz (1995) as well as Doms et al. (1997), which use plant-level data to study the relationship between wages and production technologies. At the individual level, several papers have looked at how explicit changes in the task content affect wages. A very influential study by Krueger (1993) uses micro data to study the effect of computer use on wage structure and finds that these kind of changes in tasks tend to increase wages. ${ }^{13}$

However, Proposition 2 implies that workers on equally complex tasks should be paid differently depending on the complexity of the production process they are part of. The empirical studies mentioned above do not separate the effect of change in the complexity of the entire production process from the effects of the changes in the task contents of the individual worker's own job. Here, our aim is to examine the wage differences in identical tasks across plants that have adopted production processes of different degree of complexity. This approach is related to a recent branch of the literature that studies the effects of technological changes on the organization of the firm. Studies such as Autor et al. (2003) and Bresnahan et al. (2002) have shown that technological change may affect the role of certain tasks in the production process, even when such changes have no direct effect on the content of these tasks.

Proposition 2 has a second important implication for the employer's wage policy. Consider a plant that experiences a reduction in $l$ for given level of $n$. An increase in ratio between hard tasks and easy tasks is what Johnson (1997, p. 48) has termed 'extensive 
technological change'. In this case, our model predicts that the employer will pay higher wages to all employees. Intuitively, an increase in the proportion of hard tasks leads to higher risk of production failure for any given level of effort put in by workers. Consequently, the employer has an incentive to pay higher wages to elicit more effort. ${ }^{14}$

The use of the O-ring production function is consistent with alternative wage theories. The competitive approach followed by Kremer and Maskin (1996) predicts that firms adopting complex technologies will hire high-skill, high-wage workers. Hence, increasingly complex technologies may lead to skill segregation among plants. However, the 'segregation' story proposed by Kremer and Maskin is not entirely consistent with evidence in Abowd et al. (1999a,b). Even when accounting for individual unobservables, plant characteristics explain a relevant portion of wage variability.

Another implication of the model is related to the wage gap between workers performing hard tasks and workers performing easy tasks. The following result holds: ${ }^{15}$

Proposition 3. An increase in $n$, or a decrease in $l$, will raise the wage differential between $w_{h}$ and $w_{l}$. Thus, it holds that $\mathrm{d}\left(w_{h}-w_{l}\right) / \mathrm{d}(n-l)>0$.

This result has interesting implications for the wage policy followed within a plant, and in particular for what concerns within-plant inequality. Increasing within-plant wage inequality has been observed by Davis and Haltiwanger (1991) for US manufacturing plants, and by Kramarz et al. (1996) for France. ${ }^{16}$ However, note that equation (6) implies that the wage ratio $\left(w_{h} / w_{l}\right)$ is independent of $(n-l)$. Put differently, it holds that $\log \left(w_{h}\right)-\log \left(w_{l}\right) \approx \log (z)$. Thus, the model also predicts that an increase in complexity (i.e. a higher value of $n-l$ ) tends to increase all wages within the plant by the same percentage.

To summarize, the model presented may account for two types of wage inequality:

(i) Within-group between-plant wage inequality. Our model can explain why identical workers can be paid different wages in equilibrium. According to Proposition 2, plants that adopt complex technologies will pay their workers higher wages than plants that use simple technologies.

Since harder tasks are most likely to be given to high-quality workers, our results can also account for differences in wage dispersion among heterogeneous workers:

(ii) Between-group within-plant wage inequality. Plants that adopt riskier technologies - as measured by a higher $n$, or a lower $l$-will exhibit greater wage dispersion (see Proposition 3). Consequently, the more complex the technology, the greater the level of wage inequality among high-skill and low-skill employees within plants.

\section{THE DATA}

The data used in this paper come from the wage records of the Confederation of Finnish Industry and Employers (Teollisuus ja työnantajat). Each year a survey is conducted among the member employers of the Confederation and the information is presented in the wage records. The wage records contain detailed information on the wages and working hours of all the workers who are employed in the firms affiliated with the Confederation. In the case of the metal industry in Finland, this covers practically all the firms in the industry.

In this paper, we use 1996-2000 data on the whole blue-collar worker population in the metal industry. After ruling out some workers because of missing or high probability 
of false information, we end up with a panel that has 287,587 employee/year observations containing information on 84,196 individual workers, of whom for 65,204 (77\%) we have information from two consecutive years and 34,645 (41\%) are observed in all the years 1996-2000. ${ }^{17}$ Apart from the firms, the data also identify the production plants at which the workers are employed. Workers were distributed in 369 different firms and 570 plants.

The wage records' data on wages and working hours can be considered as exceptionally reliable, since the information comes, in principle, directly from the firms' wage accounts. Apart from this information, the data contain basic individual characteristics of the workers such as gender, age, seniority and education. We also observe whether the worker is employed in single, double or triple shifts and whether the plant is located in a sparsely or densely populated area. The fact that we can observe the whole metal industry worker population also allows us to calculate the exact number of employees in each plant. Table 1 gives descriptive statistics on the data for the 1996 crosssection.

\section{(a) Wage determination in the Finnish metal industry}

The data on the metal industry are particularly useful for the analysis of the issues discussed in Section II. The reason for this is the peculiar wage determination mechanism in the Finnish metal industry. The employers and the trade union have established a procedure that provides information on the complexity of each job in this industry.

In the Finnish metal industry, the general guidelines of the wage determination are set in the national-level collective agreement that is negotiated between the central employer organization and the trade union every one to three years. According to the collective agreement, wages should be determined by the complexity of the job, by the

TABLE 1

Descriptive Statistics, 1996 Cross-Section

\begin{tabular}{lcccc}
\hline Variable & Mean & Std dev. & Min. & Max. \\
\hline Final wage & 55.28 & 8.458 & 32.5 & 154.48 \\
Complexity & 43.06 & 4.490 & 32.5 & 50.4 \\
Residual wage & 12.22 & 6.360 & 0 & 114.98 \\
Age & 38.71 & 10.56 & 14 & 65 \\
Tenure & 11.34 & 10.07 & 0 & 48 \\
Part-time & 0.011 & 0.105 & 0 & 1 \\
Female & 0.213 & 0.409 & 0 & 1 \\
New & 0.110 & 0.313 & 0 & 1 \\
Double shift & 0.221 & 0.415 & 0 & 1 \\
Triple shift & 0.195 & 0.396 & 0 & 1 \\
Years of education & 11.09 & 1.476 & 9 & \\
Plant size & 123.12 & 237.11 & & \\
Ave. plant complexity & 39.95 & 2.81 & & \\
No. observations & 57,499 & & & \\
\hline
\end{tabular}

Note: 'Complexity' refers to the occupation-related wage. 'Tenure' is the number of years the person has worked in the metal industry. Total hourly wage is in Finnish markka at year 2000 prices. 'Plant size' is the number of employees per plant.

(C) The London School of Economics and Political Science 2006 
individual performance of the worker given the requirements of the job, and by individual and firm-specific arrangements. The same rules should be applied in all the firms.

The complexity of the job specifies a job-specific minimum wage for each worker. This minimum level is called the occupation-related wage. The determination of the final wage outcome takes place at the firm level. An individual firm has considerable scope to choose its wage levels so long as the wages are set above the minimum levels set by the collective agreement.

\section{(b) Occupation-related wages}

In this paper we use occupation-related wage as our complexity measure. Occupationrelated wages are determined in the following way. The first stage of the wage determination is the evaluation of the jobs in the industry. This is carried out by a group of experts who consider various aspects of the jobs and assign them points according to their complexity. The complexity level is based on three criteria: (i) how long it takes to learn the tasks involved with the job; (ii) the degree of responsibility involved with the job, and (iii) the working conditions. The outcome of the evaluation should be independent of the characteristics of the workers and does not therefore change when the individual on the job changes or when the characteristics of the individual change.

On the basis of the expert evaluation, an occupation-related wage is determined for each job in the collective agreement. The more demanding the job, i.e. the more complexity points it gets, the higher is the corresponding occupation-related wage. This is the feature of the data that we use in the analysis. Basically, there should be a one-to-one mapping from the occupation-related wages to the complexity points. The occupationrelated wages can therefore be interpreted as a continuous variable that measures the complexity of the job. In our data we directly observe the occupation-related wages of all the workers along with their final wages. There are typically around fifty different levels of occupation-related wages per year.

Here we use the worker's own occupation-related wage as the measure of the tasks that he is performing and the average of the co-workers' occupation-related wages as the measure of the complexity of the plant's production process. While occupation-related wages are a very convenient measure of complexity, there are several problems related to their use that have to be addressed. First of all, it is crucial for our analysis that the scale with which the complexity is measured does not change in time. However, the examination of the yearly distributions of the occupation-related wages revealed that occupation-related wages were increased almost every year by a general growth factor. Table 2 reports the average final wages and occupation-related wages for 1996-2000. It is clear that they follow a similar pattern. The occupation-related wages seem to increase with final wages. It is unlikely that these increases in the occupation-related wages are related to changes in tasks.

In order to correct for these wage increases, we transformed the data by grouping the workers according to their occupation-related wages in yearly cross-sections and analysing the distributions of year-to-year changes of occupation-related wages in each group. This revealed that for most of the workers within the groups the changes in occupation-related wages were identical. Hence we interpreted the group mode of this change as the change in the occupation-related wage that was not related to changes in the tasks. The occupation-related wages were then corrected by subtracting the within-

(C) The London School of Economics and Political Science 2006 
group mode-change from the corresponding occupation-related wages. The last column of Table 2 shows the yearly means of the adjusted values of occupation-related wages. $^{18}$

Another potential problem with the use of occupation-related wages as a complexity measure is the possibility that occupation-related wages are determined ex post by final wages. Indeed, it is common that administrative job categories are simply applied to categorize individuals with similar wages rather than similar tasks. This would of course be a major problem for us, since if it were true the occupation-related wages would not reflect the complexity of the tasks. Simple wage increases would appear to change the tasks of the worker.

Figure 1 explores the relationship between the final wages and the occupation-related wages using the cross-sectional data from 1996. Statistics for the other years were virtually identical. The figure plots complexity groups and their wage distributions

TABLE 2

Unadjusted and Adjusted Average Final Wages and Occupation-Related Wages, 1996-2000

\begin{tabular}{cccc}
\hline Year & Final wage & $\begin{array}{c}\text { Occupation- } \\
\text { related wage }\end{array}$ & $\begin{array}{c}\text { Adjusted occupation- } \\
\text { related wage }\end{array}$ \\
\hline 1996 & 55.29 & 43.06 & 43.06 \\
1997 & 56.01 & 43.09 & 43.09 \\
1998 & 57.45 & 44.45 & 43.15 \\
1999 & 59.21 & 45.86 & 43.26 \\
2000 & 60.90 & 47.61 & 43.10 \\
\hline
\end{tabular}

Note: 'Final wage' refers to the average nominal wage. 'Occupation-related wage' refers to the average nominal occupation-related wage. Adjusted values are adjusted for the shifting of the complexity scale.

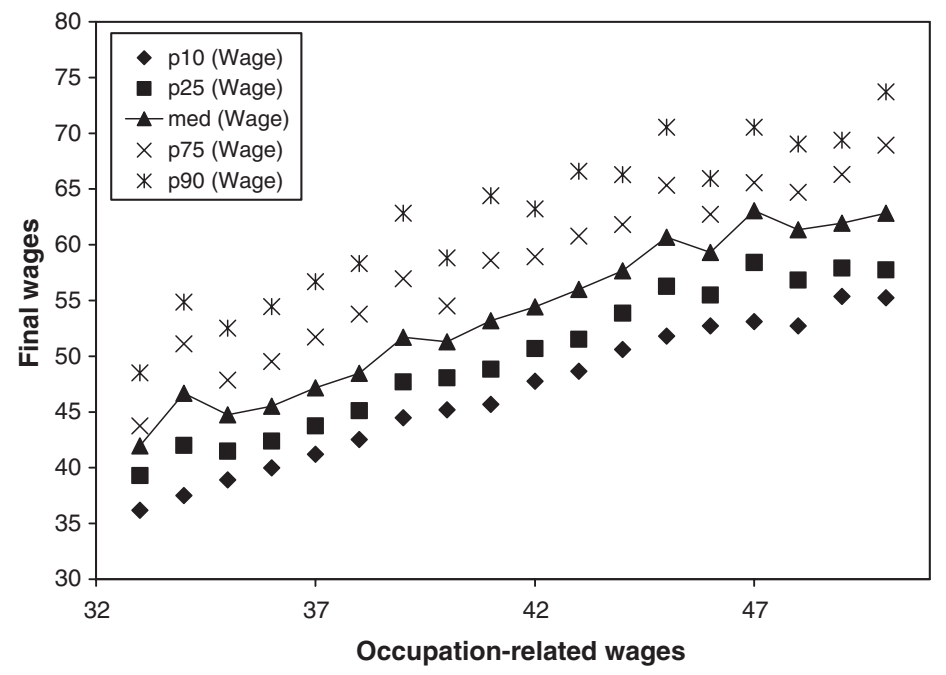

FIGURE 1. Distribution of wages as a function of the complexity of the worker's own tasks, 1996 cross-section. 
expressed by the within-group median as well as the 10th, 25th, 75th and 90th percentiles. The complexity groups were formed by aggregating the occupation-related wages into integers. There is considerable overlapping in the upper percentiles of the wage distributions, which seems to indicate that occupation-related wages are not determined by final wages.

To further assure that this is not the case, one can look at the relationship between the movement of workers across different levels of occupation-related wages and the changes in final wages. In Table 3, we look at workers who move up the complexity axis. We call these workers 'promotees'. Table 3(a) reports the positions of these workers in the within-plant wage distribution of the group they parted from. Similarly, Table 3(b) reports their position in the within-plant wage distribution of the arrival group. Groups were constructed in the same way as in Figure 1.

If occupation-related wages were determined simply by final wages, we should expect to see most of the movement taking place from the top of the wage distribution of the departure group to the bottom of the wage distribution of the arrival group. This is clearly not the case here. In fact, Table 3(a) reveals that most of the movement of promotees takes place from lower deciles of the departure group. Moreover, these workers seem to be spread more or less evenly across the deciles of the wage distribution of the arrival group, as can be seen from Table 3(b). It seems that occupation-related wages are not determined by final wages.

Finally, the use of average complexity as the measure of plant complexity also requires some justification. In the theoretical model presented above, each additional task, be it easy or hard, increases the aggregate probability of failure in the production process, which is the definition of complexity of production in Kremer's original model. However, if the number of tasks is held constant, converting a hard task into an easy task will reduce the probability of failure. Therefore, conditional on the number of tasks, the average complexity of the tasks is a valid measure of the complexity of the production process. In the regressions that follow, we always control for the number of employees in the plant. Assuming that this is a valid proxy for the number of tasks in the production process, we claim that the average complexity of the tasks is the best available measure for the complexity of the production process. ${ }^{19}$

We believe that the evidence reported above justifies the use of occupation-related wages as a measure of the complexity of the tasks in the job. Thus, for each individual, the occupation-related wage measures the complexity of the tasks she is performing, and the average occupation-related wages of her coworkers measures the complexity of the production process of the plant. ${ }^{20}$

\section{(c) Complexity and wage inequality trends in the Finnish metal industry}

Even though the availability of the complexity information is the main reason for focusing on the metal industry, we would argue that the Finnish metal industry is also suitable for this analysis in other ways. It is the largest and arguably the most successful of Finnish manufacturing industries. Furthermore, the metal industry includes the entire modern electronics sector, which in the 1990s experienced considerable expansion. While focusing on one industry naturally limits the scope of the paper, the existing literature, e.g. Dunne et al. (2004), indicates that the rise in wage inequality has largely been a within-industry phenomenon.

We were unable to explore whether there was any overall trend in the complexity of the tasks in this industry during 1990s. This was because the scale with which we 
TABLE 3

Distribution of Pay for Promotees, in Wage Deciles (\% in each decile)

\begin{tabular}{|c|c|c|c|c|c|c|c|c|c|c|c|}
\hline Level & $0 \%$ & $10 \%$ & $20 \%$ & $30 \%$ & $40 \%$ & $50 \%$ & $60 \%$ & $70 \%$ & $80 \%$ & $90 \%$ & $N$ \\
\hline \multicolumn{12}{|c|}{ (a) Before the promotion } \\
\hline 33 & 20.70 & 8.58 & 6.96 & 9.06 & 12.30 & 13.50 & 12.18 & 7.38 & 3.18 & 6.18 & 1650 \\
\hline 34 & 17.33 & 7.39 & 12.78 & 11.36 & 12.50 & 8.81 & 7.67 & 7.95 & 2.56 & 11.65 & 351 \\
\hline 35 & 18.67 & 10.27 & 7.81 & 10.42 & 13.89 & 11.65 & 7.81 & 5.50 & 2.60 & 11.36 & 1377 \\
\hline 36 & 25.08 & 7.92 & 6.27 & 5.94 & 7.59 & 6.27 & 7.92 & 6.93 & 5.94 & 20.13 & 300 \\
\hline 37 & 18.25 & 8.55 & 10.60 & 10.42 & 10.30 & 9.10 & 8.61 & 6.69 & 5.96 & 11.51 & 1651 \\
\hline 38 & 17.81 & 15.19 & 10.83 & 11.83 & 9.22 & 7.47 & 4.36 & 7.22 & 5.98 & 10.09 & 799 \\
\hline 39 & 13.18 & 7.80 & 10.49 & 11.81 & 11.12 & 9.86 & 10.70 & 7.70 & 5.48 & 11.86 & 1885 \\
\hline 40 & 10.26 & 10.26 & 11.32 & 11.98 & 10.39 & 13.04 & 11.45 & 7.54 & 6.22 & 7.54 & 1507 \\
\hline 41 & 12.77 & 9.12 & 10.95 & 10.40 & 10.68 & 10.02 & 10.02 & 10.05 & 6.44 & 9.55 & 2567 \\
\hline 42 & 10.02 & 9.66 & 16.36 & 13.91 & 13.97 & 11.01 & 9.61 & 5.45 & 4.57 & 5.45 & 1924 \\
\hline 43 & 11.25 & 8.44 & 10.58 & 11.25 & 14.42 & 9.55 & 11.16 & 8.21 & 5.40 & 9.73 & 2238 \\
\hline 44 & 8.70 & 7.97 & 11.50 & 12.29 & 14.48 & 13.02 & 8.45 & 8.88 & 7.91 & 6.81 & 1642 \\
\hline 45 & 11.82 & 8.65 & 11.38 & 13.04 & 12.85 & 10.65 & 11.38 & 7.33 & 5.08 & 7.82 & 2046 \\
\hline 46 & 7.87 & 8.34 & 8.14 & 12.38 & 13.27 & 15.25 & 14.23 & 8.89 & 6.36 & 5.27 & 1462 \\
\hline 47 & 9.36 & 8.22 & 9.45 & 9.63 & 10.16 & 14.22 & 13.25 & 10.25 & 4.86 & 10.60 & 1131 \\
\hline 48 & 6.89 & 5.21 & 7.73 & 12.10 & 15.80 & 18.82 & 11.93 & 8.40 & 5.71 & 7.39 & 595 \\
\hline 49 & 13.33 & 16.67 & 15.00 & 13.33 & 10.00 & 8.33 & 5.00 & 0.00 & 11.67 & 6.67 & 60 \\
\hline Total \% & 12.99 & 8.93 & 10.57 & 11.41 & 12.27 & 11.39 & 10.38 & 7.81 & 5.41 & 8.85 & \\
\hline$N$ & 3013 & 2076 & 2468 & 2627 & 2849 & 2648 & 2397 & 1809 & 1245 & 2053 & 23,185 \\
\hline \multicolumn{12}{|c|}{ (b) After the promotion } \\
\hline 35 & 2.64 & 3.33 & 11.48 & 25.37 & 25.83 & 19.17 & 6.66 & 2.30 & 1.38 & 1.84 & 864 \\
\hline 36 & 19.61 & 11.76 & 11.76 & 9.80 & 9.80 & 11.76 & 5.88 & 1.96 & 1.96 & 15.69 & 51 \\
\hline 37 & 16.67 & 8.33 & 10.83 & 15.14 & 16.94 & 9.17 & 8.61 & 2.92 & 3.19 & 8.19 & 712 \\
\hline 38 & 17.54 & 13.74 & 11.37 & 9.95 & 10.90 & 8.53 & 7.11 & 5.69 & 3.79 & 11.37 & 211 \\
\hline 39 & 14.80 & 10.81 & 15.95 & 14.26 & 14.57 & 9.89 & 7.67 & 3.83 & 2.68 & 5.52 & 1298 \\
\hline 40 & 10.62 & 10.76 & 13.66 & 21.93 & 14.62 & 10.90 & 7.17 & 4.28 & 2.76 & 3.31 & 724 \\
\hline 41 & 15.22 & 11.79 & 13.06 & 12.62 & 13.46 & 11.48 & 10.29 & 4.97 & 3.43 & 3.69 & 2263 \\
\hline 42 & 15.43 & 12.53 & 17.31 & 13.78 & 12.06 & 9.01 & 7.67 & 4.70 & 3.84 & 3.68 & 1275 \\
\hline 43 & 18.75 & 12.79 & 11.22 & 11.92 & 13.58 & 8.91 & 7.30 & 5.77 & 3.46 & 6.28 & 2158 \\
\hline 44 & 12.36 & 12.74 & 16.09 & 18.90 & 14.18 & 9.93 & 6.92 & 4.34 & 1.81 & 2.72 & 2090 \\
\hline 45 & 16.16 & 11.50 & 13.73 & 15.14 & 12.91 & 10.55 & 7.92 & 4.70 & 3.09 & 4.30 & 3037 \\
\hline 46 & 12.78 & 16.02 & 15.93 & 14.99 & 12.31 & 8.79 & 7.61 & 5.45 & 3.01 & 3.10 & 2123 \\
\hline 47 & 15.64 & 9.57 & 10.77 & 12.42 & 12.59 & 13.08 & 9.78 & 6.73 & 4.21 & 5.20 & 2421 \\
\hline 48 & 12.67 & 9.30 & 10.80 & 14.77 & 15.31 & 11.76 & 10.98 & 6.00 & 3.54 & 4.86 & 1666 \\
\hline 49 & 18.50 & 10.51 & 18.77 & 11.47 & 9.97 & 7.78 & 7.03 & 5.73 & 3.82 & 6.42 & 1464 \\
\hline 50 & 12.95 & 10.60 & 13.25 & 13.56 & 14.68 & 13.66 & 8.05 & 4.59 & 3.47 & 5.20 & 981 \\
\hline Total \% & 14.62 & 11.33 & 13.74 & 14.73 & 13.79 & 10.73 & 8.25 & 5.02 & 3.20 & 4.60 & 100.00 \\
\hline$N$ & 3399 & 2681 & 3217 & 3442 & 3214 & 2490 & 1918 & 1165 & 735 & 1078 & 23,339 \\
\hline
\end{tabular}

Note: 'Promotees' are workers who move from a given complexity level to a higher one. Complexity levels are constructed by aggregating the occupation-related wages into integers. Rows report the distribution of promotees in the wage deciles of the within-plant wage distribution of given level after the promotion takes place. Columns are deciles of the within-plant wage distribution of that level. Column $N$ reports the number of promotees from each complexity group. Row $N$ reports the number of promotees from each wage decile.

measured complexity was bounded from above and constant over time. However, complexity of the tasks within plants was fairly persistent. Year-to-year variation in the plant level means of occupation-related wages was small and concentrated around zero. 
Standard measures of wage inequality, such as standard deviation of wages and the ratio of the 10th and 90th percentiles of wages, remained almost constant throughout the decade. There is no indication whatsoever that wage inequality would have increased in the Finnish metal industry during these years. However, there are some signs of increasing segregation of both tasks and wages across plants. The index of segregation suggested by Kremer and Maskin (2000) (1996, revised version), which measures the extent of within-plant correlation of the complexity of the tasks, increased from 0.41 in 1996 to 0.46 in 2000. Similarly, the segregation of wages increased from 0.50 in 1996 to 0.58 in 2000 . There are signs that plants were becoming increasingly different with respect to each other in terms of both complexity and wages.

\section{THE RESUlTS}

The theory presented in Section I has two major implications. First of all, the within-task wage differences should increase between plants as the dispersion of the complexity of the production processes increases. Hence, controlling for the complexity of the tasks of the individual worker, we should find a positive effect of the complexity of the production process on wages. Second, the increasing complexity of the production process should increase between-task wage differences within plants. This implies that wages should increase more steeply with the complexity of the tasks in plants that have adopted more complex production processes. In this section we study these implications empirically.

\section{(a) Plant complexity and the wage dispersion within tasks}

As explained in the previous section, we measure the complexity of the tasks with taskspecific minimum wages (occupation-related wages). Thus, if the implications of the theory are right, plants with more complex production processes, i.e. with higher average occupation-related wages, should pay more on top of the occupation-related wages than the plants with less complex production processes. In what follows, we refer to the difference between the final wage and the occupation-related wage as the residual wage. Hence, the theory implies that residual wages should increase with the complexity of the production process.

In Figure 2 we plot average plant-level residual wages against average occupationrelated wages in the plant in 1996 cross-section. The figure shows clearly that the relationship between the average complexity of the tasks in the plant and the willingness of the plant to pay on top of the occupation-related wages is positive. However, it is not clear whether this correlation reflects the effect of plant complexity on wages. After all, there are many unobservables, at both plant and individual level, that can affect wages and be correlated with the complexity of the plant's production process at the same time.

In order to account for the effects of observable and unobservable individual and plant characteristics, we estimate the following residual wage equation:

$$
w_{i, t}^{r e s}=\beta_{1} \bar{n}_{J(i, t), t}+\beta_{2}\left[\bar{n}_{J(i, t), t}\right]^{2}+X_{i, t} \gamma+\mu_{J(i, t)} \alpha_{i}+\delta_{J(i, t)}+\varepsilon_{i, t}
$$

where $w_{i, t}^{r e s}$ is the real residual hourly wage of an individual $i$ at time $t, \bar{n}_{J(i, t), t}$ is our measure of the complexity of the production process of the plant $J(i, t)$, where $i$ is employed at $t, X_{i, t}$ is a set of observable individual and plant characteristics, and $\varepsilon_{i, t}$ is the residual. 


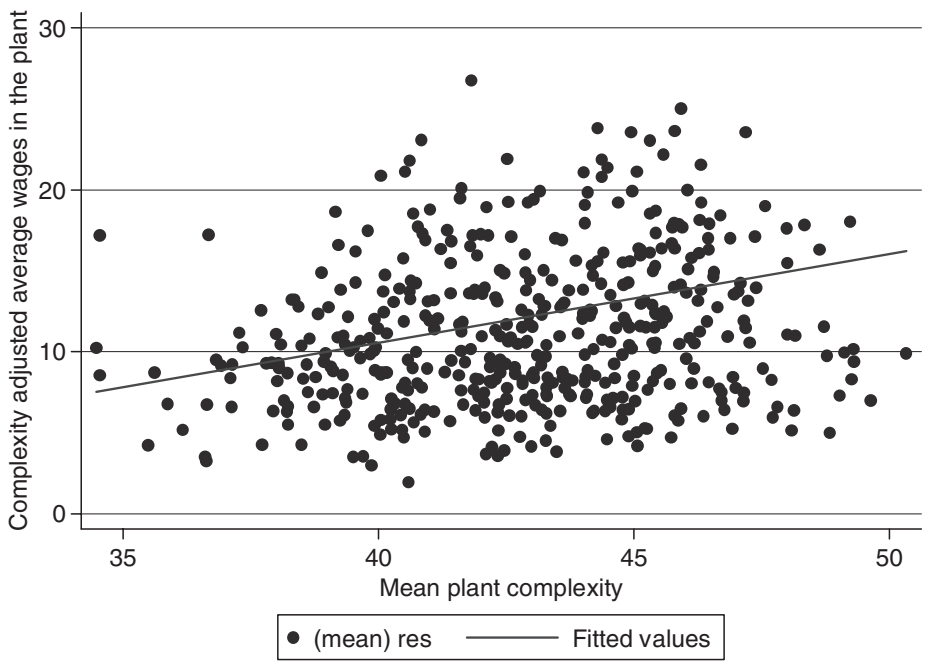

FIGURE 2. The average residual and occupation-related wages in the plants, 1996 cross-section. Plant-size weighted OLS is super-imposed. Coefficient is 0.55 and the standard error 0.01 .

As explained in Section II, we measure the production process with the $i$ 's coworkers' average occupation-related wages at the plant $J(i, t)$. After conducting various experiments, we decided to use the quadratic functional form in (10) since this seemed to fit the data best. In $X_{i, t}$ we include quadratic terms of the age and seniority of the worker, years of education, a dummy for female worker, shift work, and newcomer in the industry, the number of employees at the plant, and a linear time trend.

In equation (10), $\alpha_{i}$ and $\delta_{J(i, t)}$ are the unobservable individual and plant effects, respectively. We assume that both $\alpha_{i}$ and $\delta_{J(i, t)}$ are fixed in time, but we allow the effect of individual unobservables to vary across plants. The factor loading $\mu_{J(i, t)}$ represents the within-plant returns to unobservable individual characteristics.

It seems plausible that the unobserved individual ability, $\alpha_{i}$, is correlated with the complexity of the worker's own task and the complexity of the plant. After all, the output in more complex tasks should be more sensitive to a worker's ability, and because of this the employers might want to assign the high ability workers to more complex tasks. Similarly, plants with complex production processes may offer higher returns to unobserved ability, and thus attract high-ability workers.

Because of the potential correlation between unobservable ability and our complexity variables, the estimation of (10) with OLS would yield biased estimates. We address this problem by exploiting the panel nature of the data. More precisely, we control for factors that make an individual more productive in a given plant by transforming (10) into first differences within plant-individual matches, i.e.

$$
\Delta w_{i, t}^{r e s}=\beta_{1} \Delta \bar{n}_{J(i, t), t}+\beta_{2} \Delta\left[\bar{n}_{J(i, t), t}\right]^{2}+\gamma \Delta X_{i, t}+\Delta \varepsilon_{i, t},
$$

and estimating (11) by OLS. This procedure yields consistent estimates of $\beta_{1}$ and $\beta_{2}$ provided that the observables in (10) are not correlated with $\varepsilon_{i, t}$.

In (11), the variation in the valuation of individual ability across plants is absorbed by differencing within plant-individual matches. Thus, the movement of workers that is driven by the differences in the valuation of both observable and unobservable skills does not bias the estimates of $\beta$ 's in (11). The identification of $\beta$ 's in (11) is based on the 
observations of workers who stay within the same plant and comes from the changes in the plant-level complexity over time.

Table 4 presents results from different specifications of our residual wage equation. As a benchmark case, we present the results from the OLS estimation of (10) in levels in the first column. In the second column, equation (10) is first-differenced within individuals and firm dummies are excluded. This specification assumes that individual fixed effects, $\alpha_{i}$, are equally valued across plants and that the plant unobservables, $\delta_{J(i, t)}$, are not correlated with the other explanatory variables. To allow for the latter possibility, in column (3), a full set of 570 plant dummies is introduced into the equation. Finally, in the fourth column we present the results from the OLS estimation of (11), where the firstdifferencing is done within individual-plant pairs.

The pooled OLS estimate of the effect of plant complexity from equation (10) is positive and decreasing and is clearly significant. The same pattern was repeated when we estimated the equation in yearly cross-sections. As was to be expected, the effect of the complexity of the production process on wages is considerably reduced once the unobservables at both individual and plant level are controlled for. When only the individual effects are included, the estimates of $\beta$ 's are halved but they remain significant. The introduction of a full set of 570 plant dummies further decreases the estimates of $\beta$ 's, whereas allowing for the heterogeneous valuation of individual effects across plants does not seem to have an effect on the estimates.

These results clearly indicate that an increase in the complexity of the co-workers' tasks has a positive effect on the worker's own hourly wage. In Table 5 we report the marginal effects of plant complexity at different points of the plant complexity distribution. Using these marginal effects, one can calculate the elasticity of residual wages with respect to changes in plant complexity. Our preferred estimates, the ones obtained in the specification in column (4) that controls for both plant and individual fixed effects and allows the latter to be differentially valued across plants, suggest that at the mean value the effect of plant complexity is 0.15 . This implies that a 1 percentage point increase in the complexity of the production process increases a worker's residual wages by 0.46 percentage point. However, taking into account that residual wages are on average $21 \%$ of the final wages, this translates to an elasticity of 0.10 in final wages.

\section{(b) Plant complexity and the wage dispersion between tasks}

Proposition 3 predicts that differences in wage levels between difficult and easy tasks should increase as the production technology of the plant becomes more complex. This implies that, on average, the wage dispersion between tasks should be higher in relatively more complex plants.

Figure 3 provides a crude way of looking at the relationship between plant complexity and the dispersion of wages between tasks. In this Figure, we plot the differences between the average levels of final wages in 'high' and 'low' complexity tasks against plant complexity in the 1996 cross section. High-complexity tasks were defined as tasks whose occupation-related wages fell in the four top groups in Figure 1. Similarly, the low-complexity tasks were defined as tasks whose occupation-related wages fell in one of the four lowest groups in Figure 1. Of the 467 plants in the 1996 cross-section, 218 had both low and high-complexity tasks.

Figure 3 suggests that the within-plant wage differences between high and lowcomplexity tasks are higher in high-complexity plants. The pattern was very similar for the years 1997-2000. Also, more conventional measures of within-plant wage dispersion,

(C) The London School of Economics and Political Science 2006 
TABLE 4

Regression Analysis of the Residual Wage Function

\begin{tabular}{|c|c|c|c|c|}
\hline & $\begin{array}{l}\text { OLS in } \\
\text { levels }\end{array}$ & $\begin{array}{c}(2) \\
\text { First } \\
\text { differences } \\
\text { within } \\
\text { individuals }\end{array}$ & $\begin{array}{l}\text { (3) } \\
\text { First differences } \\
\text { within individuals } \\
\text { with a full set of } \\
\text { plant dummies }\end{array}$ & $\begin{array}{c}\text { (4) } \\
\text { First differences } \\
\text { within (individual } \times \\
\text { plant) pairs }\end{array}$ \\
\hline Plant complexity & $\begin{array}{l}4.087 \\
(2.084)\end{array}$ & $\begin{array}{l}2.110 \\
(0.601)^{* * * *}\end{array}$ & $\begin{array}{l}1.743 \\
(0.613)^{* * *}\end{array}$ & $\begin{array}{l}1.635 \\
(0.621)^{* * *}\end{array}$ \\
\hline$(\text { Plant complexity })^{2}$ & $\begin{array}{r}-0.044 \\
(0.024)\end{array}$ & $\begin{array}{c}-0.024 \\
(0.007)^{* * *}\end{array}$ & $\begin{array}{l}-0.020 \\
(0.007)^{* * *}\end{array}$ & $\begin{array}{c}-0.018 \\
(0.007)^{* * *}\end{array}$ \\
\hline Age $/ 10$ & $\begin{array}{l}4.302 \\
(0.429)^{* * *}\end{array}$ & & & \\
\hline$(\text { Age } / 10)^{2}$ & $\begin{array}{l}-0.456 \\
(0.053)^{* * *}\end{array}$ & $\begin{array}{l}-0.896 \\
(0.112)^{\text {*** }}\end{array}$ & $\begin{array}{l}-0.914 \\
(0.111)^{* * *}\end{array}$ & $\begin{array}{l}-0.945 \\
(0.111)^{* *}\end{array}$ \\
\hline Tenure & $\begin{array}{l}2.919 \\
(0.423)^{* * *}\end{array}$ & & & \\
\hline$(\text { Tenure })^{2}$ & $\begin{array}{l}-0.600 \\
(0.107)^{* * *}\end{array}$ & $\begin{array}{l}-0.439 \\
(0.176)^{*}\end{array}$ & $\begin{array}{l}-0.376 \\
(0.174)^{*}\end{array}$ & $\begin{array}{c}-0.355 \\
(0.180)^{*}\end{array}$ \\
\hline Female dummy & $\begin{array}{l}-2.885 \\
(0.342)^{* * *}\end{array}$ & & & \\
\hline Double shift dummy & $\begin{array}{c}0.585 \\
(0.373)\end{array}$ & $\begin{array}{c}0.043 \\
(0.136)\end{array}$ & $\begin{array}{c}0.016 \\
(0.136)\end{array}$ & $\begin{array}{c}0.059 \\
(0.121)\end{array}$ \\
\hline Triple shift dummy & $\begin{array}{r}-0.588 \\
(0.615)\end{array}$ & $\begin{array}{r}-0.046 \\
(0.171)\end{array}$ & $\begin{array}{r}-0.111 \\
(0.164)\end{array}$ & $\begin{array}{r}-0.099 \\
(0.162)\end{array}$ \\
\hline Years of education & $\begin{array}{c}0.001 \\
(0.043)\end{array}$ & $\begin{array}{l}0.158 \\
(0.059)^{* *}\end{array}$ & $\begin{array}{c}0.150 \\
(0.059)^{*}\end{array}$ & $\begin{array}{c}0.153 \\
(0.061)^{*}\end{array}$ \\
\hline Sparse area dummy & $\begin{array}{r}-0.907 \\
(0.775)\end{array}$ & $\begin{array}{c}0.518 \\
(0.273)\end{array}$ & $\begin{array}{l}0.904 \\
(0.259)^{* * *}\end{array}$ & $\begin{array}{l}0.911 \\
(0.256)^{* * *}\end{array}$ \\
\hline Plant size $/ 100$ & $\begin{array}{c}0.908 \\
(0.356)^{*}\end{array}$ & $\begin{array}{r}-0.021 \\
(0.258)\end{array}$ & $\begin{array}{c}0.319 \\
(0.517)\end{array}$ & $\begin{array}{c}0.271 \\
(0.541)\end{array}$ \\
\hline Trend & $\begin{array}{l}0.156 \\
(0.104)\end{array}$ & $\begin{array}{l}1.178 \\
(0.101)^{\text {*** }}\end{array}$ & $\begin{array}{l}1.203 \\
(0.104)^{* * *}\end{array}$ & $\begin{array}{l}1.231 \\
(0.103)^{* * *}\end{array}$ \\
\hline Constant & $\begin{array}{c}-92.622 \\
(45.281)^{*}\end{array}$ & & & \\
\hline Plant dummies & None & None & 570 & None \\
\hline Observations & 287,758 & 196,610 & 196,610 & 189,114 \\
\hline$R^{2}$ & 0.17 & 0.02 & 0.05 & 0.02 \\
\hline $\begin{array}{l}\text { Test for the joint } \\
\text { significance of } \\
\text { plant complexity } \\
\text { and its square }\end{array}$ & $\begin{array}{c}F(2,569)=5.70 \\
P=0.004\end{array}$ & $\begin{array}{c}F(2,514)=6.72 \\
P=0.001\end{array}$ & $\begin{array}{c}F(2,569)=4.12 \\
P=0.017\end{array}$ & $\begin{array}{c}F(2,488)=3.54 \\
P=0.030\end{array}$ \\
\hline
\end{tabular}

Note: **Refers to significance at $5 \%$ level. *Refers to significance at $10 \%$ level. Age is divided by 10 . 'Tenure' is the number of years the individual has worked in the firm divided by 10. 'Plant-size' refers to the number of employees in the firm divided by 100 . Plant complexity is measured as the mean of the real occupation-related wages of individual's co-workers. Standard errors, reported in parentheses, are corrected for heteroskedasticity using Huber-White formula accounting for the fact that there are multiple observations per plant. Column (1) reports the results from the estimation of equation (10) in levels. Column (2) reports the results from the estimation of equation (11) differenced within individuals and omitting the plant dummies. Column (3) reports the results from the estimation of equation (11) differenced within individuals and including a full set of plant dummies. Column (4) reports the estimation results from the estimation of equation (11) differenced within (individual $\times$ plant) pairs. The final row reports the $F$-test statistics for the joint significance of plant complexity and plant complexity squared. 
TABLE 5

Estimated Marginal Effects of Plant Complexity at Different Points of the Plant COMPleXity Distribution

(1)

(2)

(3)

First differences

within individuals First differences

\begin{tabular}{lccccc} 
Percentiles & $\begin{array}{c}\text { Plant } \\
\text { complexity }\end{array}$ & $\begin{array}{c}\text { OLS in } \\
\text { levels }\end{array}$ & $\begin{array}{c}\text { First differences } \\
\text { within individuals }\end{array}$ & $\begin{array}{c}\text { with a full set of } \\
\text { plant dummies }\end{array}$ & $\begin{array}{c}\text { within (individual } \times \\
\text { plant) pairs }\end{array}$ \\
\hline $10 \%$ & 37.07 & 0.825 & 0.331 & 0.260 & 0.300 \\
$25 \%$ & 38.99 & 0.656 & 0.238 & 0.183 & 0.231 \\
Mean & 41.19 & 0.462 & 0.133 & 0.095 & 0.152 \\
$75 \%$ & 43.44 & 0.264 & 0.025 & 0.005 & 0.071 \\
$90 \%$ & 45.25 & 0.105 & -0.062 & -0.067 & 0.006 \\
\hline
\end{tabular}

Note: Estimated marginal effects of plant complexity from the models in Table 4. Column (1) reports the marginal effects from the equation (10) in levels. Column (2) reports the marginal effects from equation (11) differenced within individuals and omitting the plant dummies. Column (3) reports the marginal effects from equation (11) differenced within individuals and including a full set of plant dummies. Column (4) reports the marginal effects from equation (11) differenced within (individual $\times$ plant) pairs.

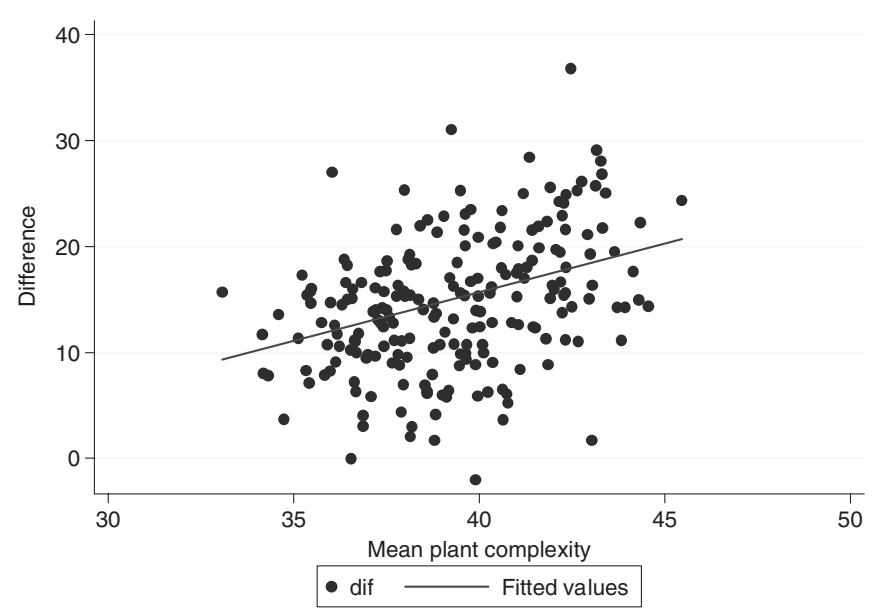

FIGURE 3. The wage difference between high and low complexity tasks and the plant complexity, 1996 cross-section.

Plant-size weighted OLS is superimposed. Coefficient is 0.82 and the standard error 0.01 .

such as the standard deviation of what the plant pays on top of the occupation-related wage, were positively correlated with the average complexity of the tasks in the plant.

Generalizing to multiple task levels, the theory indicates that, in the plants that have adopted more complex production processes, the wage levels should rise more steeply with the complexity of the worker's own tasks. In order to see whether this is the case, we grouped plants into coarse complexity groups according to their average occupationrelated wages. We followed the same logic as in the grouping of workers in Figure 1. That is, we first rounded the average plant occupation-related wages into integers and then grouped plants according to these numbers. This resulted in 15 plant complexity groups. $^{21}$ We then regressed final wages on individual complexity and the same set of

(C) The London School of Economics and Political Science 2006 
TABLE 6

Regression Analysis of the Wage Function in Levels within Plant Complexity Groups: INDIVIDUAL $\times$ PLANT EFFECTS

\begin{tabular}{lccr}
\hline $\begin{array}{l}\text { Plant complexity } \\
\text { groups }\end{array}$ & $\begin{array}{c}\text { Coefficient of } \\
\text { individual } \\
\text { complexity }\end{array}$ & $\begin{array}{c}\text { No. of } \\
\text { individuals }\end{array}$ & $\begin{array}{r}\text { No. of } \\
\text { plants }\end{array}$ \\
\hline 36 & $0.178(0.125)$ & 1,418 & 11 \\
37 & $0.459^{* * *}(0.142)$ & 3,305 & 19 \\
38 & $0.602^{* * *}(0.043)$ & 12,270 & 41 \\
39 & $0.544^{* * *}(0.080)$ & 9,503 & 62 \\
40 & $0.479^{* * *}(0.063)$ & 9,283 & 81 \\
41 & $0.467^{* * *}(0.084)$ & 12,378 & 100 \\
42 & $0.448^{* * *}(0.050)$ & 17,307 & 120 \\
43 & $0.451^{* * *}(0.117)$ & 19,378 & 111 \\
44 & $0.290^{* * *}(0.088)$ & 28,213 & 95 \\
45 & $0.708^{* * *}(0.174)$ & 34,673 & 95 \\
46 & $0.661^{* *}(0.086)$ & 20,965 & 89 \\
47 & $0.800^{* * *}(0.138)$ & 12,775 & 56 \\
48 & $0.584^{* * *}(0.095)$ & 5,506 & 35 \\
49 & $0.694^{* * *}(0.202)$ & 1,033 & 9 \\
50 & $1.032^{* *}(0.089)$ & 910 & 9 \\
\hline
\end{tabular}

Note: Dependent variable real hourly wage in levels. The coefficient of the individual complexity in levels is reported. All the regressions use the same set of controls as in Table 4. Groups 36-50 refer to complexity groups that were constructed by rounding the average occupation-related wages in the plant to nearest integers. Standard errors, reported in parentheses, are corrected for heteroskedasticity using the Huber-White formula, accounting for the fact that there are multiple observations per plant.

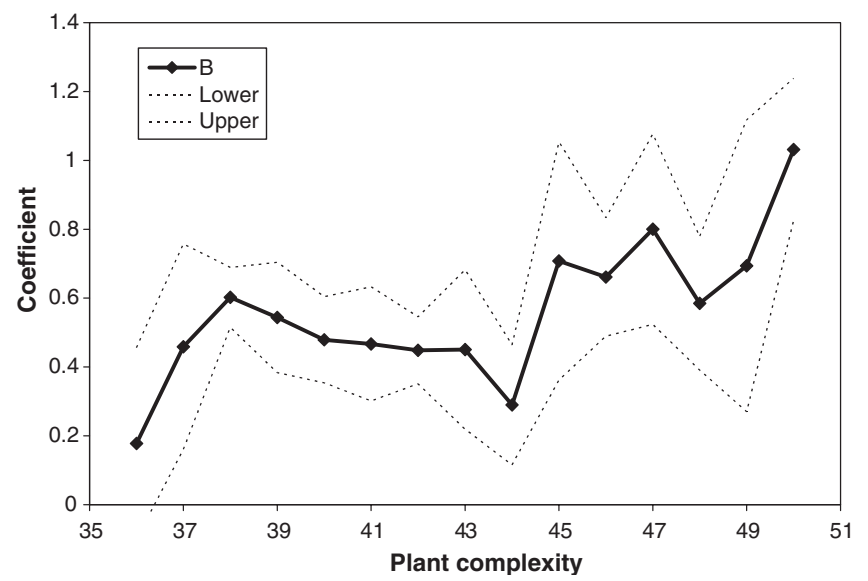

FIGURE 4 . The estimated coefficients and $95 \%$ confidence intervals of individual complexity by plant complexity groups.

controls as in the regression (11) within these groups. If the wage dispersion between tasks of different complexity is increasing with plant complexity, we would expect to see higher coefficients of individual complexity in the high-plant-complexity groups.

The results of this exercise are reported in Table 6 . To save space, we report only the estimated coefficients of individual complexity. The coefficients, along with 95\% confidence intervals, are plotted against plants' complexity in Figure 4. As can be seen 
from Table 6 and Figure 4, the effect of the complexity of the worker's own tasks is highest in group 50. In general, the coefficients of individual complexity tend to increase with plant complexity, although not monotonically. These results suggest that a worker switching from a low-complexity task to a more demanding task in a plant that has adopted a very complex production process obtains, on average, a higher wage increase than that he would obtain by doing the same switch in a plant with a less complex production process. We interpret these results as being supportive of the wage dispersion implications of the theory discussed in Section I.

\section{CONCLUDING REMARKS}

The idea that an employer's characteristics, such as the features of technology, drive the firm's wage policy has been widely discussed. As argued by Krueger and Summers (1987, 1988), technological factors seem to be very relevant for explaining wage structures over different countries. Moreover, Katz (1986) and Gibbons and Katz (1992) have noted that inter-industry wage 'relativities' are remarkably similar in different occupations. On the basis of Katz's evidence, Layard et al. (1991, p. 167) have concluded that 'this is not at all consistent with a technological approach. Why should the responsibilities of office workers, janitors, technicians, and operatives in different industries all vary in proportion? It seems most unlikely.' However, the objection raised by Layard et al. is not valid when technology is represented by an O-ring production function. In the O-ring perspective, production succeeds when a number of interdependent operations are performed correctly. Consequently, ill performance by an electrician in the production of airplanes can have more dramatic consequences than that electrician's sloppy performance in the car industry. The model we propose implies that heterogeneity in technological complexity across plants generates both (i) within-task, between-plant wage dispersion, and (ii) between-task, within-plant wage dispersion. These predictions are broadly supported by evidence from a unique dataset of Finnish metalworkers.

\section{APPENDIX}

The problem with using occupation-related wages as a measure of the complexity of the tasks is that they are increased in some years by a general growth factor that is not related to real changes in tasks (see also Pekkarinen 2003). Figure A1 plots the yearly distributions of occupation-related wages and reveals that in some years the whole distribution of the occupation-related wages shifts. It is clear that the complexity of the tasks cannot undergo such changes. Thus, in order to use the occupation-related wages as a measure of the complexity of the tasks, we need to clear away these changes.

We corrected the occupation-related wages from this kind of change by constructing two-year samples of workers who (i) were present in both years $t$ and $t+1$, (ii) did not change their occupational code, and (iii) did not change firms between the two years. Thus, we ended up with four separate samples of workers with two observations per worker in each. The idea was to have samples of workers who remained in the same tasks in years $t$ and $t+1$ and to observe the changes in their occupation-related wages.

We grouped the workers in each two-year sample according to their occupation-related wages in year $t$ and analyzed the distributions of year-to-year changes in the occupation-related wages of each group. This analysis revealed that, for most of the workers within a group, the year-to-year changes in occupation-related wages were identical. Thus, we interpreted the group mode of the change of occupation-related wage as the increase in occupation-related wage that is not related to changes in the tasks. All the rest of the changes were interpreted as a change in tasks.

(C) The London School of Economics and Political Science 2006 


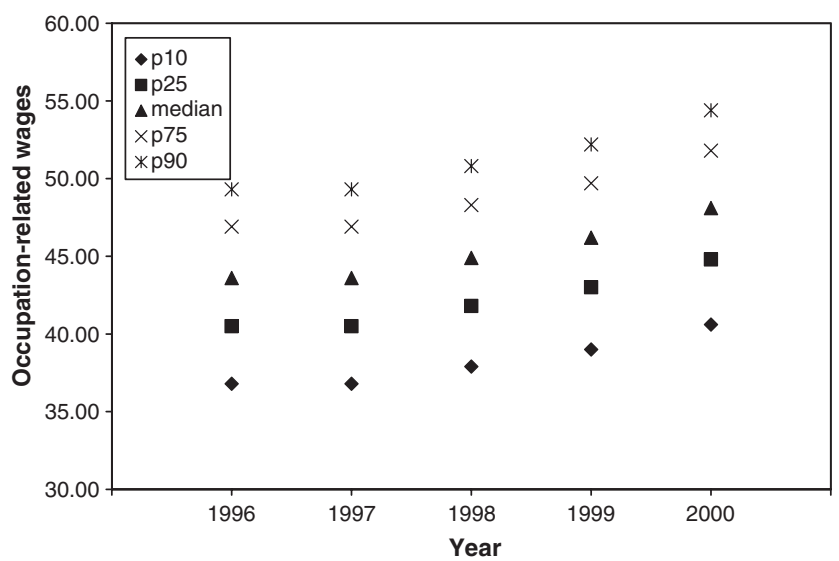

FIGURE A1. Yearly distributions of occupation-related wages, 1996-2000.

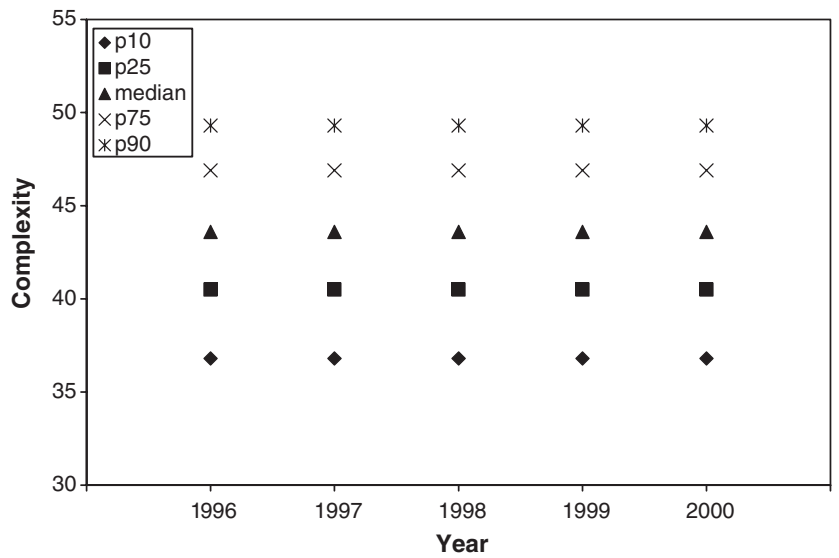

FIGURE A2. Yearly distributions of adjusted occupation-related wages, 1996-2000.

The occupation-related wages were then corrected in order to make them correspond to complexity by substracting from each occupation-related wage the mode of the change of the occupation-related wage of the workers with the same value of occupation-related wage. Figure A2 plots the yearly distributions of the corrected occupation-related wages.

\section{ACKNOWLEDGMENTS}

We are very grateful to Andrea Ichino and two anonymous referees for helpful comments. We also thank the Confederation of Finnish Industry and Employers (Teollisuus ja työnantajat) for the permission to use their wage records. The data are archived at the Labour Institute for Economic Research, Helsinki, and permission to use the data is controlled by the Confederation of Finnish Industry and Employers. Pekkarinen gratefully acknowledges financial support from the Academy of Finland, the Finnish Work Environment Fund and the Yrjö Jahnsson Foundation.

\section{NOTES}

1. See, among many others, Berman et al. (1994), Autor et al. (1998), Berman et al. (1998), Doms et al. (1997), Goldin and Katz (1996, 1998), Haskel and Heden (1999) and Machin and Van Reenen (1998).

2. On within-group inequality, see e.g. Gottschalk (1997) and Acemoglu (1999).

3. Similar ideas are put forward by Milgrom and Roberts $(1990,1995)$.

(C) The London School of Economics and Political Science 2006 
4. These implications are supported by evidence on Finnish metalworkers provided in Pekkarinen (2002).

5. On within-plant wage inequality, see Entorf et al. (1999) and the references quoted therein.

6. We abstract from physical capital in the production function. The inclusion of capital leaves the main results unaltered.

7. High-quality workers are assigned to difficult jobs in the original Kremer (1993) model and in the assignment models surveyed by Sattinger (1993). Kremer and Maskin (1996) analyse the firm's optimal matching decision when workers intrinsically have different productivity.

8. The model can also capture the special case where all workers are identical. In this case the employer will have to hire workers of the same quality to perform tasks of different complexity. It follows that $x_{h}=x_{l}$, and condition (6) implies that workers assigned to harder tasks will be paid more. Then, since workers of equal skills are paid different wages, this special case clarifies that what drives wage dispersion here is not workers' quality, but the fact that different tasks within a plant are differentially sensitive to effort.

9. See the example of the printing industry reported in Mark (1987). See also Bresnahan (1999) on whitecollar tasks.

10. The zero-profit condition determines $f^{*}$, the equilibrium number of firms operating in the market.

11. The determinant associated with the system (8)-(9) is negative. The proof of Proposition 2 is rather immediate, although it requires some tedious calculations.

12. For evidence on plant segregation, see Davis and Haltiwanger (1991), and, in particular, Kremer and Maskin (1996). Verhoogen (2004) and Kaplan and Verhoogen (2005) reach similar conclusions from evidence on the Mexican manufacturing sector. After the Peso crises in 1994, quality upgrading in production has led to higher wages in exporting firms. These differentials are mostly due to plant-level wage-premia.

13. However, DiNardo and Pischke (1997), as well as Entorf et al. (1999), attribute this effect to unobserved individual heterogeneity.

14. The model also implies that $\mathrm{d} w_{h} / \mathrm{d} F$ and $\mathrm{d} w_{l} / \mathrm{d} F$ are positive. Firms that bear high fixed costs, as measured by $F$, tend to safeguard their investment by paying high wages, so as to obtain a better performance from their workers. Fixed costs can capture different kinds of sunk investment, such as irreversible equipment, or R\&D itself. Moreover, the amount of fixed costs is likely to be related to the firm's size, measured by the number of times the basic production process is replicated. Also note that $\mathrm{d} w_{h} / \mathrm{d} z$ and $\mathrm{d} w_{l} / \mathrm{d} z$ are positive: when hard tasks become even more sensitive to effort, the firm will pay higher wages to all workers.

15. To verify Proposition 3, note that $\mathrm{d}\left(w_{h}-w_{l}\right) / \mathrm{d} n=[1-(1 / z)]\left(\mathrm{d} w_{h} / \mathrm{d} n\right)>0$, since $z>1$.

16. According to Entorf et al. (1999), this phenomenon is accounted for-at least in part-by the introduction of new technologies.

17. In addition, 8325 employee/year observations $(2.9 \%)$ were dropped because of potentially false or missing data.

18. In the Appendix we provide a more detailed description of this adjustment to occupation-related wages.

19. We also experimented with other moments of the within-plant complexity distribution, such as skewness. However, while these variables had the expected sign in the OLS regressions, there was not enough within-individual variation to identify their effect in the fixed effects regressions.

20. We chose to calulate the complexity of the production process at the level of plants instead of firms. It seems that plants are closer to the actual production units that the theory describes.

21. There were two other groups where the number of plants was too small (2 and 6) to conduct a reasonable analysis.

\section{REFERENCES}

Abowd, J. M., Kramarz, F. and Margolis, D. N. (1999a). High wage workers and high wage firms. Econometrica, 67, 251-333.

— , Finer, H. and Kramarz, F. (1999b). Individual and firm heterogeneity in compensation: an analysis of matched longitudinal employer-employee data for the state of Washington. In J. C. Haltiwanger et al. (eds.), The Creation and Analysis of Employer-Employee Matched Data. Amsterdam: North-Holland.

Acemoglu, D. (1999). Changes in unemployment and wage inequality: an alternative theory and some evidence. American Economic Review, 89, 1259-78.

Autor, D. H., KAtz, L. F. and Krueger, A. B. (1998). Computing inequality: have computers changed the labor market? Quarterly Journal of Economics, 113, 1169-1213.

—, Levy, F. and Murnane, R. (2003). The skill content of recent technological change: an empirical exploration. Quarterly Journal of Economics., 118, 1279-1333.

Berman, E., Bound, J. and Griliches, Z. (1994). Changes in the demand for skilled labor within US manufacturing: evidence from the annual survey of manufacturers. Quarterly Journal of Economics, 109, 367-97.

- Bound, J. and MACHIN, S. (1998). Implications of skill-biased technological change: international evidence. Quarterly Journal of Economics, 113, 1245-79. 
Bresnahan, T. F. (1999). Computerisation and wage dispersion: an analytical reinterpretation. Economic Journal, 109, 390-415.

, BRYNJOLFSSON, E. and HitT, L. M. (2002). Information technology, workplace organization, and the demand for skilled labor: firm-level evidence. Quarterly Journal of Economics, 117, 339-76.

Dalmazzo, A. (2002). Technological complexity, wage differentials and unemployment. Scandinavian Journal of Economics., 104, 515-530.

Davis, S. J. and Haltiwanger, J. (1991). Wage dispersion between and within U.S. manufacturing plants, 1963-86. Brooking Papers on Economic Activity: Microeconomics, 115-180.

DiNARdo, J. E. and PischKe, J.-S. (1997). The returns to computer use revisited: have pencils changed the wage structure too? Quarterly Journal of Economics, 112, 291-303.

Doms, M., Dunne, T. and Troske, K. R. (1997). Workers, wages, and technology. Quarterly Journal of Economics, 112, 253-90.

Dunne, T. and Schmitz, J. A. Jr. (1995). Wages, employment structure and employer size-wage premia: their relationship to advanced-technology usage at US manufacturing establishments. Economica, 62, 89-107.

—, Foster, L., Haltiwanger, J. and Troske, K. (2004). Wage and productivity dispersion in United States manufacturing: the role of computer investment. Journal of Labor Economics, 22, 397-429.

Entorf, H., Gollac, M. and Kramarz, F. (1999). New technologies, wages, and worker selection. Journal of Labor Economics., 17, 464-91.

Gibbons, R. S. and Katz, L. F. (1992). Does unmeasured ability explain inter-industry wage differentials? Review of Economic Studies, 59, 515-36.

Goldin, C. and KATZ, L. F. (1996). Technology, skill, and the wage structure: insights from the past. American Economic Review, Papers and Proceedings, 86, 252-7.

and (1998). The origins of technology-skill complementarity. Quarterly Journal of Economics, 93, 693-732.

GotTschalK, P. (1997). Inequality, income growth, and mobility: the basic facts. Journal of Economic Perspectives, 11, 21-40.

Haskel, J. and Heden, Y. (1999). Computers and the demand for skilled labour: industry and establishmentlevel panel evidence for the UK. Economic Journal, 109, C68-79.

Johnson, G. E. (1997). Changes in earnings inequality: the role of demand shifts. Journal of Economic Perspectives, 11, 41-54.

Kaplan, D. S. and Verhoogen, E. (2005). Exporting and individual wage premia: evidence from Mexican employer-employee data. Mimeo, Columbia University, New York.

KATZ, L. F. (1986). Efficiency wage theories: a partial evaluation. NBER Macroeconomics Annual 1986, Cambridge, Mass.: MIT Press.

Kramarz, F., Lollivier, S. and Pelè, L.-P. (1996). Wage inequalities and firm-specific compensation policies in France. Annales d'Economie et de Statistique, 41-42, 369-86.

KREMER, M. (1993). The O-ring theory of economic development. Quarterly Journal of Economics, 108, 551-75. - and MASKin, E. (1996). Wage inequality and segregation by skill. NBER Working Paper no. 5718, Cambridge, Mass.; revised version March 2000.

KRUEGER, A. B. (1993). How computers have changed the wage structure: evidence from microdata, 1984 1989. Quarterly Journal of Economics, 108, 33-60.

— and Summers, L. H. (1987). Reflections on the inter-industry wage structure. In K. Lang and J. S. Leonard (eds.), Unemployment and the Structure of Labor Markets. pp. 17-47. Oxford: Basil Blackwell.

— and (1988). Efficiency wages and the inter-industry wage structure. Econometrica, 56, $259-93$.

Layard, R., Nickell, S. and JACKMAn, R. (1991). Unemployment: Macroeconomic Performance and the Labour Market. Oxford: Oxford University Press.

Machin, S. and VAn REEnEn, J. (1998). Technology and changes in skill structure: evidence from seven OECD countries. Quarterly Journal of Economics, 113, 1215-44.

MARK, J. A. (1987). Technological change and employment: some results from BLS research. Monthly Labor Review, 110, 26-29.

Milgrom, P. and Roberts, J. (1990). The economics of modern manufacturing: technology, strategy, and organization. American Economic Review, 80, 511-28.

Milgrom, P. and Roberts, J. (1995). Complementarities and fit. Strategy, structure, and organizational change in manufacturing. Journal of Accounting and Economics, 19, 179-208.

PekKarinen, T. (2002). Complexity, wages, and the O-ring production function: evidence from Finnish panel data. Labour Economics, 9, 531-46.

(2003). Complex production processes and wage inequality. Mimeo, Nuffield College, Oxford. 
SAtTinger, M. (1993). Assignment models of the distribution of earnings. Journal of Economic Literature, 31, 831-80.

Summers, L. H. (1988). Relative wages, efficiency wages, and keynesian unemployment. American Economic Review Papers and Proceedings, 78, 383-8.

VERHOOGEN, E. (2004). Trade, quality upgrading and wage inequality in the mexican manufacturing sector: theory and evidence from an exchange-rate shock. Mimeo, Columbia University, New York. 